\title{
Study of Liver Function Test in COVID-19 Patients and Its Correlation with Inflammatory Markers from Hubballi, Karnataka
}

\author{
Kalinga Bommanakatti Eranaik ${ }^{1}$, Uday Subhash Bande², L.M. Veeresh ${ }^{3}$ \\ 1,2,3Department of General Medicine, Karnataka Institute of Medical Sciences, Hubballi, Karnataka, India.
}

\section{ABSTRACT}

\section{BACKGROUND}

Since its reporting in December 2019, SARC-COV-2 (COVID -19) has infected more than 230 million people over the world by colonising the respiratory tract, however very little is known about its effect on liver and how the liver injury affects disease prognosis. This study was done to assess the hepatic profile in SARC-COV-2 infection along with inflammatory markers.

\section{METHODS}

This is a single centred prospective observational study. 400 patients with real time polymerase chain reaction (PCR) confirmed COVID 19 infection admitted in KIMS, Hubballi were taken for study. Patients with decompensated liver disease were excluded from the study. Clinical examination and laboratory investigations including liver function test (LFT), renal function test (RFT), complete blood count (CBC), chest X-ray, D-dimer, ferritin, lactate dehydrogenase (LDH), C reactive protein (CRP) was done for all the patients.

\section{RESULTS}

Out of the 400 covid-19 positive patients admitted, 286 (71.5 \%) had abnormal liver enzymes. Significantly raised liver enzymes were seen in males. Raised liver enzymes and inflammatory markers were associated with poor outcome of the disease. Significant reduced albumin was associated with poor outcome of the disease. Significantly raised aspartate transaminase (AST), alanine transaminase (ALT) levels were associated with increased severity of the disease. $(P=0.009$ and 0.029 respectively). Significant positive relation was found between liver profile and inflammatory markers.

\section{CONCLUSIONS}

Majority of patients admitted with SARS-CoV-2 had deranged liver profile. Higher proportion of abnormal liver enzymes were seen in males. Degree of liver injury increases with increasing severity of the disease. Even though abnormal liver enzymes were positively associated with elevated inflammatory markers and severity of the disease, more studies are needed to study implications of liver injury in prognosis of SARS-CoV-2 infection.

\section{KEY WORDS}

Liver Function Test, SARS-CoV-2 Infection. Hepatocellular Injury, Cholestatic Injury, Inflammatory Markers.
Corresponding Author:

Dr. L.M. Veeresh,

Room No. 194, Vivek Hostel,

KIMS Campus, Vidyanagar,

Hubballi-580021, Karnataka, India.

E-mail:veeresh953863@gmail.com

\section{DOI: 10.14260/jemds/2021/795}

How to Cite This Article:

Eranaik KB, Bande US, Veeresh LM. Study of liver function test in COVID - 19 patients and its correlation with inflammatory markers from Hubballi, Karnataka. J Evolution Med Dent Sci 2021;10(45):39363940, DOI: 10.14260/jemds/2021/795

Submission 13-11-2021,

Peer Review 20-11-2021,

Acceptance 13-12-2021,

Published 28-12-2021.

Copyright (C) 2021 Kalinga Bommanakatti Eranaik et al. This is an open access article distributed under Creative Commons Attribution License [Attribution 4.0 International (CC BY 4.0)] 


\section{BACKGROUND}

COVID - 19 was first reported in December 2019 in Wuhan city of China and is caused by severe acute respiratory syndrome corona virus - $2 .{ }^{1}$ Despite aggressive measures, it has spread to more than 200 countries and as of October 2021, it has infected more than 233 million people and killed more than 4.7 million people globally. ${ }^{2}$

Corona virus belonging to the family coronaviridae are RNA viruses infecting birds and mammals by targeting the respiratory tract. ${ }^{3}$ Though COVID - 19 patients come with respiratory symptoms, extra pulmonary manifestations are not uncommon. ${ }^{4}$ COVID - 19 is a systemic disease with multiple target organs like lung, heart, intestine, liver, kidney and lymph nodes. ${ }^{5}$

Liver is a very important organ in our body. It is a storehouse of many vitamins and minerals. Liver removes potential toxin from the body by metabolising them into simple non-toxic by-products. Liver also synthesises many proteins and coagulating factors. Liver is a storehouse of glycogen which serves as an immediate source of energy in times of need. Liver also helps to fight infections by removing bacteria from the portal circulation. Liver metabolises haeme into bile which is responsible for absorption of fat soluble vitamins. Liver converts toxic ammonia into urea which is later excreted through kidneys.

Liver injury in SARS - CoV - 2 infection is thought to be multifactorial which includes direct cytopathic effects of virus on hepatocytes, sepsis and cytokine mediated injury, uncontrolled immune response and drug induced liver injury. COVID - 19 causing multi organ dysfunction and cytokine storm leading to acute surge in levels of IL - 6, IL - 2, INF - $\Upsilon$ and IL - 10 which directly causes damage to liver and also influences disease severity. A recent study found that SARS - CoV - 2 binds to angiotensin converting enzyme 2 (ACE2) receptors present in bile duct cells or cholangiocytes facilitating viral entry and replication resulting in both direct and immune mediated hepatic injury.6,7 Post-mortem study of liver of COVID - 19 patient showed viral RNA along with micro vesicular steatosis with lobular involvement.8,9 Small amount of viral particles were also detected in blood stream of patients. Hence it is possible that the viral particles reach the liver through portal circulation. According to certain studies, raised liver function parameters are linked to poor clinical outcomes in COVID - 19 patients, including longer hospital stays, a higher risk of severe COVID - 19 disease, and mortality. ${ }^{10-12}$

This dysregulation of liver dysfunction is represented biochemically as derangement of liver enzymes. This study aims to study the type of liver injury by analysing liver enzymes and total bilirubin and its correlation with different inflammatory markers in patients infected with SARS - CoV 2.

\section{METHODS}

This is a single centred prospective observational study. 400 patients of both genders admitted in KIMS (Karnataka Institute of Medical Sciences), Hubballi which is a tertiary care centre with COVID - 19 positive status were retrospectively analysed. Patients from Dharwad district admitted from June to September of 2021 were taken for the study. All patients over the age of 16 years were included in the study. Patients below the age of 16 years, pregnant women and those with decompensated liver disease were excluded from the study. Patients name, age, sex along with clinical data including laboratory investigations and chest radiographs and outcome was collected. All the patients were segregated into mild, moderate and severe category based on clinical severity and assessment parameters according to updated clinical management protocol for COVID - 192021 given by Government of India, Ministry of Health and Family Welfare. ${ }^{13}$

\section{Laboratory Methods}

COVID - 19 positive status were based on the results of SARS - CoV - 2 RNA tests in nasopharyngeal or throat swab specimens using the polymerase chain reaction method. Following standard precautionary methods, blood sample was taken by designated person with wearing personal protection equipment. Early morning samples were taken and centrifuged for 10 minutes. Serum samples for liver function tests, CRP and ferritin were analysed in Transasia XL 1000 auto analyser. Samples for D-dimer were analysed by ECL 105 single channel coagulation analyser. Tests were performed according to standard protocols and procedures provided by Erba Mannheim company.

\section{Parameters for Liver Function Test and Inflammatory Markers}

Abnormal liver function tests were defined as elevation of following parameters in serum: total bilirubin (TB) $>1.2$ $\mathrm{mg} / \mathrm{dl}$, albumin $<3.5 \mathrm{~g} / \mathrm{L}$, aspartate transaminase (AST) $>40$ $\mathrm{U} / \mathrm{L}$, alanine transaminase (ALT) $>40 \mathrm{U} / \mathrm{L}$ and alkaline phosphatase (ALP) > $128 \mathrm{U} / \mathrm{L}$. COVID - 19 is a new emerging infectious illness, and classifications for liver injury aren't yet established. In this study, hepatocellular injury is defined as raised AST or ALT more than 3 times the upper limit of normal range and cholestatic injury is defined as raised ALP more than 2 times the upper limit of normal range. Mixed liver injury is defined as presence of AST/ALT more the 3 times upper limit and ALP more than 2 times the normal limit.

Raised inflammatory markers were defined as D-dimer $>$ $500 \mathrm{ng} / \mathrm{dl}, \mathrm{CRP}>10 \mathrm{mg} / \mathrm{L}$, serum LDH > $280 \mathrm{U} / \mathrm{L}$, serum ferritin $>400$ in males and $>250$ in females.

\section{Statistical Analysis}

Data was entered in Microsoft ${ }^{\mathrm{TM}}$ Excel and analysed using $\mathrm{R}$ software. ${ }^{14}$ Categorical variables were summarised as frequency and percentage, continuous variables were summarised as mean (SD), median (IQR). Categorical variables were analysed using chi square test. Relation between two continuous variables were analysed using Pearson's correlation. $\mathrm{P}$ value $<0.05$ was considered as statistically significant. 


\section{RESULTS}

Out of the 400 covid-19 positive patients admitted, 268 (67 $\%)$ were males and 132 (33\%) were females. 41 (10.3\%), 69 $(17.3 \%)$ and $290(72.5 \%)$ patients belonged to mild, moderate and severe categories respectively. Out of 400 patients, 286 (71.5\%) patients had abnormal liver enzymes out of which 28 patients had hepatocellular and/or cholestatic injury. Out of 286, 214 patients had abnormal AST/ALT, 21 patients had pure abnormal ALP and 72 patients had mixed pattern.

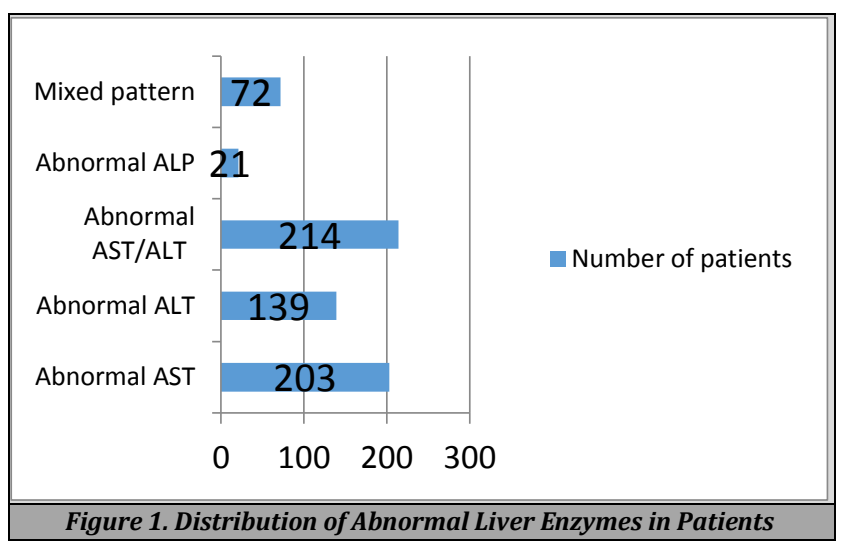

\begin{tabular}{|ccccc|}
\hline \multirow{4}{*}{ AST } & Normal & Male (\%) & Female (\%) & Chi Square Test \\
& Abnormal & $185(69.3)$ & $49(37.1)$ & \\
& Hepatocellular injury & $18(6.7)$ & $79(59.8)$ & $\mathrm{P}=0.015$ \\
ALT & Normal & $129(48.1)$ & $85(64.4)$ & \\
& Abnormal & $129(48.1)$ & $43(32.6)$ & $\mathrm{P}=0.009$ \\
& Hepatocellular injury & $10(3.7)$ & $4(3)$ & \\
ALP & Normal & $214(79.9)$ & $93(70.5)$ & \\
& Abnormal & $47(17.5)$ & $36(27.3)$ & $\mathrm{P}=0.078$ \\
& Cholestatic injury & $7(2.6)$ & $3(2.3)$ & \\
\hline \multicolumn{5}{c}{ Table 1. Comparison of Liver Enzymes with Gender } \\
\hline
\end{tabular}

Mean age of patients was 56.72 overall. $71.7 \%$ of males had raised AST levels compared to $62.8 \%$ in females. $51.8 \%$ had raised ALT levels compared to $35.6 \%$ in females. However, $20.1 \%$ had raised ALP levels compared to $29.6 \%$ in females.

\begin{tabular}{|cccc|}
\hline & Discharge & Death & P Value \\
Age & $55.53+/-15.52$ & $60.11+/-14.13$ & 0.003 \\
Albumin & $3.0+/-0.66$ & $2.63+/-0.65$ & 0.012 \\
Total Billirubin & $0.75+/-1.69$ & $0.72+/-0.61$ & 0.854 \\
AST & $54.69+/-43.06$ & $76.74+/-73.93$ & 0.048 \\
ALT & $43.05+/-29.01$ & $64.55+/-70.64$ & 0.042 \\
ALP & $103.43+/-83.38$ & $119.62+/-104.92$ & 0.1 \\
CRP & $53.17+/-33.49$ & $61.7+/-30.09$ & 0.016 \\
D dimer & $1773+/-2480.48$ & $2901+/-4550.76$ & 0.002 \\
Ferritin & $443.38+/-281.43$ & $566.06+/-305.5$ & $<0.005$ \\
\hline Table 2. Comparison of Demographical and Laboratory Data (Mean \\
+/-SD) Including Liver Enzymes of COVID - 19 Patients with Outcome \\
\hline \multicolumn{4}{l}{}
\end{tabular}

Mean age of death was significantly lower in patients that got discharged compared to those who died (55.53 compared to 60.11 years). Albumin was significantly lower in the patients who succumbed due to disease (3 compared to 2.63 $\mathrm{g} / \mathrm{dl}$ ). Similarly total bilirubin, AST, ALT, CRP, D dimer and ferritin were higher in patients who succumbed to the disease. Hepatocellular enzymes like AST and ALT showed significant correlation in between patients who were discharged and declared with $\mathrm{P}$ values of 0.048 and 0.042 respectively. Mean AST levels were $54.59 \mathrm{U} / \mathrm{L}$ in discharged group compared to $76.74 \mathrm{U} / \mathrm{L}$ in declared group. Mean ALT levels were 43.05 in discharged group compared to 64.55
U/L in declared group. Inflammatory markers like CRP, D dimer and ferritin showed significant association between the two groups with $\mathrm{P}$ values of $0.016,0.002$ and $<0.005$ respectively.

\begin{tabular}{|c|c|c|c|c|}
\hline & & $\begin{array}{l}\text { Discharge } \\
(\%)\end{array}$ & $\begin{array}{l}\text { Death } \\
(\%)\end{array}$ & $\begin{array}{l}\text { Chi Square } \\
\text { Test }\end{array}$ \\
\hline \multirow{3}{*}{ AST } & Normal & $86(75.4)$ & $28(24.6)$ & \multirow{3}{*}{$P=0.103$} \\
\hline & Abnormal & $178(67.4)$ & $86(32.6)$ & \\
\hline & Hepatocellular injury & $14(63.6)$ & $8(36.4)$ & \\
\hline \multirow{3}{*}{ ALT } & Normal & $156(72.9)$ & $58(27.1)$ & \multirow{3}{*}{$P=0.084$} \\
\hline & Abnormal & $114(66.3)$ & $58(33.7)$ & \\
\hline & Hepatocellular injury & $8(57.1)$ & $6(42.9)$ & \\
\hline \multirow{3}{*}{ ALP } & Normal & $224(73)$ & $83(27)$ & \multirow{3}{*}{$P=0.011$} \\
\hline & Abnormal & $48(57.8)$ & $35(42.2)$ & \\
\hline & Cholestatic injury & $6(60)$ & $4(40)$ & \\
\hline \multicolumn{5}{|c|}{$\begin{array}{c}\text { Table 3. Comparison of Degree of Derangement of Liver Enzymes } \\
\text { with Outcome of Patients }\end{array}$} \\
\hline
\end{tabular}

The degree of derangement of liver enzymes were correlated with outcome of the disease. ALP was found to have significant association with outcome of the disease $(\mathrm{P}=$ 0.011) whereas AST and ALT did not show significant association with the outcome (Table 3). However when the levels of enzymes were categorised into normal, abnormal and hepatocellular injury, worsening levels of AST and ALT were significantly associated with severity of COVID - 19 disease with $\mathrm{P}$ value of 0.009 and 0.029 respectively (Table 4).

\begin{tabular}{|c|c|c|c|c|c|}
\hline & & $\begin{array}{l}\text { Mild ( } n= \\
41)\end{array}$ & $\begin{array}{c}\text { Moderate } \\
(n=69)\end{array}$ & $\begin{array}{c}\text { Severe } \\
(n=290)\end{array}$ & $\begin{array}{c}\text { Chi Square } \\
\text { Test }\end{array}$ \\
\hline \multirow{3}{*}{ AST } & Normal & 22 & 21 & 75 & \multirow{3}{*}{$P=0.009$} \\
\hline & Abnormal & 18 & 44 & 198 & \\
\hline & $\begin{array}{l}\text { Hepatocellular } \\
\text { injury }\end{array}$ & 1 & 4 & 17 & \\
\hline \multirow{3}{*}{ ALT } & Normal & 32 & 38 & 148 & \multirow{3}{*}{$P=0.029$} \\
\hline & Abnormal & 8 & 29 & 131 & \\
\hline & $\begin{array}{l}\text { Hepatocellular } \\
\text { injury }\end{array}$ & 1 & 2 & 11 & \\
\hline \multirow{3}{*}{ ALP } & Normal & 29 & 51 & 227 & \multirow{3}{*}{$P=0.466$} \\
\hline & Abnormal & 12 & 16 & 55 & \\
\hline & $\begin{array}{l}\text { Hepatocellular } \\
\text { injury }\end{array}$ & 0 & 2 & 8 & \\
\hline & Table 4. Com & $\begin{array}{l}\text { ison of } \\
\text { ity of } C\end{array}$ & $\begin{array}{l}\text { rity of Lii } \\
\text { D-19 Dise }\end{array}$ & $\begin{array}{l}\text { er Injury } w \\
\text { se }\end{array}$ & \\
\hline
\end{tabular}

Mean value of total protein in discharged and death groups were $6.05 \mathrm{~g} / \mathrm{dl}$ and $6.15 \mathrm{~g} / \mathrm{dl}$ respectively. Mean values of albumin were $3 \mathrm{~g} / \mathrm{dl}$ and $2.63 \mathrm{~g} / \mathrm{dl}$ respectively $(\mathrm{P}<$ $0.05)$. Levels of bilirubin was relatively same $(0.49$ and 0.57 $\mathrm{g} / \mathrm{dl}$ respectively) in both the groups.

\begin{tabular}{|ccccccc|}
\hline & \multicolumn{2}{c}{ CRP } & \multicolumn{2}{c}{ D-dimer } & \multicolumn{2}{c|}{ Ferritin } \\
& r & P & r & P & r & P \\
Albumin & -0.341 & $<0.005$ & -0.051 & 0.307 & -0.097 & 0.053 \\
TB & 0.034 & 0.492 & 0.076 & 0.131 & 0.121 & 0.016 \\
AST & 0.021 & 0.677 & 0.167 & 0.001 & 0.106 & 0.034 \\
ALT & 0.09 & 0.071 & 0.094 & 0.059 & 0.044 & 0.377 \\
ALP & 0.105 & 0.036 & 0.08 & 0.11 & 0.072 & 0.15 \\
\hline Table 5. Correlation of Liver Function Parameters with Inflammatory \\
Markers Using Pearson's Correlation (r) and P Value \\
\hline
\end{tabular}

The liver function tests were correlated with inflammatory enzymes with the help of Pearson quotient and $P$ value. Albumin being a negative acute phase reactant had a significant negative correlation with CRP, D-dimer and ferritin levels. Positive correlation was seen between other liver function parameters including total bilirubin (TB), AST, ALT and ALP with CRP, D-dimer and ferritin levels. C reactive protein showed significant association with albumin $(\mathrm{p}<$ $0.005)$ and ALP $(p=0.036)$. D-dimer showed significant association with AST $(\mathrm{p}=0.001)$. Ferritin levels showed significant association with TB $(\mathrm{p}=0.016)$ and AST $(\mathrm{p}=$ 0.034). 


\section{DISCUSSION}

Liver function tests include various parameters like markers of hepatocellular injury (AST, ALT), markers of bile duct injury (ALP), synthetic capacity of liver (Albumin) and markers of bile clearance (serum bilirubin). These parameters are however not specific for liver. ALP can be elevated in diseases of bone and aminotransferases can be elevated in myosite injury. SARS-CoV-2 infection is a multisystem inflammatory disease with predominant involvement of respiratory system, however it also produces significant inflammatory response in gastrointestinal and hepato-biliary system thereby warranting need for present study.

Out of 400 COVID-19 positive patients studied in this study, 286 (71.5\%) had abnormal liver enzymes which is comparable with study done by Cai $\mathrm{Q}$ et al. which showed nearly $76.3 \%$ of patients had abnormal liver enzymes. ${ }^{11}$ This significant association in patients with no previous decompensated liver disease suggests viral mediated liver injury. SARS-CoV-2 uses ACE2 receptor for docking and entry into the cells. ${ }^{7}$ ACE2 receptors are present in plenty in cholangiocytes through which virus causes liver dysfunction. ${ }^{8}$ In our study AST, ALT, ALP enzymes were significantly elevated in males compared to females $(\mathrm{P}<$ 0.05 ) which is consistent with the Wuhan based study which attributes it to increased ACE2 receptor expression in male. ${ }^{15,16}$ Higher proportion of males had abnormal liver enzymes compared to females in our study which is comparable to study by Saini RK et al. where $67.4 \%$ males had abnormal liver enzymes compared to $46.03 \%$ in females. Age is a important risk factor for mortality in SARSCoV-2 infection $(P=0.003)$. Worsening levels of liver enzymes showed significant association with increasing age which is consistent with previous studies. ${ }^{17,18}$

Patients who succumbed due to disease had significantly raised AST and ALT when compared to people who recovered $(\mathrm{p}=0.048$ and 0.042 respectively). Cholestatic injury showed significant association with mortality $(\mathrm{p}=$ 0.011). Though patients with hepatocellular injury were more in number compared to cholestatic injury (23 compared to 10), hepatocellular damage did not show significant association with outcome. Severe manifestations of SARS - CoV - 2 infection leading to death are associated with increasingly severe liver derangement which is consistent with the previous studies. ${ }^{10-12}$

According to one previous study, viral particles were not identified in liver biopsy of patient who died of COVID - 19. Hence, apart from ACE2 receptor mediated entry to liver cells suggesting direct cytotoxicity of liver cells, other mechanisms have been postulated. Immune dysregulation, cytokine storm and pneumonia related hypoxia have also been attributed to liver damage. Antiviral drugs used in treatment of disease may also contribute to liver injury. Similarly severity of derangement of AST and ALT showed significant correlation with severity of disease in our study (P $=0.009$ and 0.029 respectively). There is direct association between extent of liver damage and clinical severity of the disease.

Patients who succumbed to disease had significantly lower albumin levels compared to their counterparts $(\mathrm{p}=$
0.012). Severe disease is associated with poor nutrition, abnormal metabolism and cytokine storm. Albumin is a negative acute phase reactant and hence its synthesis is down regulated during the disease. However, total protein did not have significant association with severity of disease probably because of correspondingly raised globulin levels which is consistent with Wuhan based study. ${ }^{19}$ Hypoalbuminemia leads to generalised deterioration of health status. As albumin is a major transporter of various vitamins and minerals, patients suffer from malnutrition resulting in poor body defence mechanism and further deterioration.

CRP, D-dimer and serum ferritin are inflammatory markers and are significantly elevated in severe COVID - 19 disease. ${ }^{20}$ Similarly they showed significant association with outcome of the disease in present study $(\mathrm{P}<0.05)$. When liver enzymes were correlated with inflammatory markers, significant positive correlation was observed suggesting increased levels of liver enzymes are associated with elevated inflammatory markers. Similarly elevated markers in COVID - 19 is associated with increased severity and poor prognosis. ${ }^{21}$ Hence, increased markers reflective of inflammation and cytokine storm is associated with raised liver enzymes suggesting immune mediated damage of liver cells.

D - dimer in blood signifies fibrin degradation products. Endothelitis and fibrin micro thrombi have been described in liver sinusoids which lead to luminal thrombosis, portal tract fibrosis. This is responsible for coagulopathy, raised D-dimer, reduced liver perfusion and shock. Accordingly, significantly higher D-dimer were seen in patients with hepatocellular injury and in patients who succumbed due to the disease.

Though $71.5 \%$ of patients had deranged liver enzymes, only 28 patients $(7 \%$ ) had significant liver injury (cholestatic or hepatocellular). Previous studies have reported mild and clinically insignificant levels of liver damage in COVID - 19 patients with minimal impact on outcomes. ${ }^{22}$ Hence, even though liver enzymes are associated with severity and outcome of the disease, more studies are needed to study significance of liver injury in increasing severity and outcome of COVID - 19 disease.

\section{CONCLUSIONS}

COVID - 19 affects liver by multiple mechanisms leading to deranged liver profile. Patients with increased risk of severe disease and mortality have severely deranged liver profile. Abnormal liver enzyme is associated with elevated inflammatory markers. Liver function test being a routine test can help in prognostication of COVID - 19 disease and provide scope for improving management. However, still more studies are needed to study implications of liver injury in prognosis of the disease.

\section{Limitations of the Study}

This is a single centre based retrospective observational study lacking detailed history and epidemiological characteristics. Medication history of patients were not known. Hence role of drugs (anti virals) in liver injury could not be studied. 
Data sharing statement provided by the authors is available with the full text of this article at jemds.com.

Financial or other competing interests: None.

Disclosure forms provided by the authors are available with the full text of this article at jemds.com.

\section{REFERENCES}

[1] Zhu NA, Zhang D, Wang W, et al. A novel coronavirus from patients with pneumonia in China, 2019. N Engl J Med 2020;382(8):727-33.

[2] WHO Coronavirus Disease. (COVID-19) dashboard. Available from: https://COVID 19.who.int/

[3] Dong Y, Liang X, Yu X. Prognostic value of the dynamic changes in extra vascular lung water index and angiopoietin-2 in severe multiple trauma patients with acute respiratory distress syndrome. Zhonghua Wei Zhong Bing Ji Jiu Yi Xue 2019;31(5):571-6.

[4] World Health Organization. Communicable disease surveillance \& response (CSR). Severe Acute Respiratory Syndrome (SARS). Available from: http://www.who.int/csr/sars/en

[5] To KF, Tong JHM, Chan PKS, et al. Tissue and cellular tropism of the coronavirus associated with severe acute respiratory syndrome: an in-situ hybridization study of fatal cases. J Pathol 2004;202(2):157-63.

[6] Chai X, Hu L, Zhang Y, et al. Specific ACE2 expression in cholangiocytes may cause liver damage after 2019-nCoV infection. Bio Rxiv 2020.

[7] Zhou P, Yang XL, Wang XG, et al. A pneumonia outbreak associated with a new coronavirus of probable bat origin. Nature 2020;579:270-3.

[8] Xu Z, Shi L, Wang Y, et al. Pathological findings of COVID19 associated with acute respiratory distress syndrome. Lancet Respir Med 2020;8(4):420-422.

[9] Zhang C, Shi L, Wang FS. Liver injury in COVID-19: management and challenges. Lancet Gastroenterol Hepatol 2020;5(5):428-30.

[10] Zhou F, Yu T, Du R, et al. Clinical course and risk factors for mortality of adult inpatients with COVID-19 in Wuhan, China: a retrospective cohort study. Lancet 2020;395(10229):1054-62.

[11] Cai Q, Huang D, Yu H, et al. COVID-19: abnormal liver function tests. J Hepatol 2020;73(3):566-74.
[12] Phipps MM, Barraza LH, LaSota ED, et al. Acute Liver Injury in COVID-19: Prevalence and Association with Clinical Outcomes in a Large US Cohort. Hepatology 2020;72(3):807-17.

[13] Government of India. Ministry of Health and Family Welfare (MOHFW). Available from: htpps://www.mohfw.gov.in/pdf/UpdatedDetailedClinic alManagementProtocolforCOVID19adultsdated2405202 1 (accessed 4 October 2021)

[14] R Core Team. R: A language and environment for statistical computing. $\mathrm{R}$ Foundation for Statistical Computing, Vienna, Austria. 2021. URL https://www.Rproject.org/.

[15] Zhao S, Lin Q, Ran J, et al. Preliminary estimation of the basic reproduction number of novel coronavirus (2019$\mathrm{nCoV}$ ) in China, from 2019 to 2020: a data-driven analysis in the early phase of the outbreak. Int J Infect Dis 2020;92:214-7.

[16] Zhou C. Evaluating new evidence in the early dynamics of the novel coronavirus COVID-19 outbreak in Wuhan, China with real time domestic traffic and potential asymptomatic transmissions. medRxiv 2020.

[17] Saini RK, Saini N, Ram S, et al. COVID-19 associated variations in liver function parameters: a retrospective study. Postgrad Med J 2020;postgradmedj-2020138930.

[18] Bangash MN, Patel J, Parekh D. COVID-19 and the liver: little cause for concern. Lancet Gastroenterol Hepatol 2020;5(6):529-30.

[19] Zhang Y, Zheng L, Liu L, et al. Liver impairment in COVID-19 patients: a retrospective analysis of 115 cases from a single centre in Wuhan city, China. Liver Int 2020;40(9):2095-103.

[20] Wang D, Hu B, Hu C, et al. Clinical characteristics of 138 hospitalized patients with 2019 novel coronavirusinfected pneumonia in Wuhan, China. JAMA 2020;323(11):1061-9.

[21] Guo Y, Korteweg C, McNutt MA, et al. Pathogenetic mechanisms of severe acute respiratory syndrome. Virus Res 2008;133(1):4-12.

[22] Mehta P, McAuley DF, Brown M, et al. COVID-19: consider cytokine storm syndromes and immunosuppression. Lancet 2020;395(10229):1033-4. 